\title{
PRIMARY CLOSURE OF CBD WITH ANTEGRADE STENTING FOR CHOLEDOCHOLITHIASIS
}

Nagesh Nayakarahalli Swamygowda ${ }^{1}$, Balakrishna Nanjundappa Setty2, Sridhara Kolala Govindaiah ${ }^{3}$, Kaushik Subramanian ${ }^{4}$, Venugopal Hunasanahalli Giriyappa ${ }^{5}$, Vinay Boppasamudra Nanjegowda ${ }^{6}$, Savitha Krishna Gowda Karlwad ${ }^{7}$

1 Professor and HOD, Department of Surgical-Gastroenterology, Bangalore Medical College and Research Institute, Bangalore. ${ }^{2}$ Assistant Professor, Department of Surgical-Gastroenterology, Bangalore Medical College and Research Institute, Bangalore. ${ }^{3}$ Resident, Department of Surgical-Gastroenterology, Bangalore Medical College and Research Institute, Bangalore.

${ }^{4}$ Resident, Department of Surgical-Gastroenterology, Bangalore Medical College and Research Institute, Bangalore.

${ }_{5}^{5}$ Associate Professor, Department of Surgical-Gastroenterology, Bangalore Medical College and Research Institute, Bangalore.

${ }^{6}$ Professor, Department of Surgical-Gastroenterology, Bangalore Medical College and Research Institute, Bangalore.

${ }^{7}$ Senior Resident, Department of Surgical-Gastroenterology, Bangalore Medical College and Research Institute, Bangalore.

\section{ABSTRACT}

\section{BACKGROUND}

Traditional teaching has been to close the Common Bile Duct (CBD) over a T-tube after exploration for stone disease. With the advent of ERCP and medical grade biliary stents, the art of T-tube placement seems to be on the wane. We aim to present our experience of primary closure of the CBD with antegrade stenting after CBD exploration.

\section{MATERIALS AND METHODS}

A retrospective descriptive study (Audit) was performed from the operating room database of our hospital for those patients who underwent primary closure of the CBD with antegrade stenting (Both Laparoscopic and Open) during the period of 2007 - 2015 . A systematic record review with review of the OT notes with special emphasis on intraoperative findings and post-procedural complications was carried out.

\section{RESULTS}

The study period saw a total of 88 patients being operated; 65 in Group 1 (Antegrade stenting) and 23 in Group 2 (T tube). Most frequent presenting complaint was obstructive pattern of jaundice followed by right upper quadrant pain, fever and a combination in both the study groups. A total of 39 (60\%) females and $26(40 \%)$ males underwent surgery in Group 1 (Range 18 - 75 years, Mean 37 years). The average operative duration in the open CBDE was 146 mins, whereas the LCBDE arm had a mean duration of 186 mins. The mean hospital stay was 3 days for LCBDE patients (Range 2 - 4) and 5 days for OCBDE patients (Range 3 - 7). No patients in the study Group 1 required re-intervention or repeated imaging. Patients were aged between 26 and 75 years with a median age of 50 years in Group 2 with 9 males and 12 females. The mean operative time in T-tube group (Group 2) was $113.26 \pm$ 21.62 mins. T-tube cholangiogram was carried out on POD-14 as a protocol before removal of T-tube.

\section{CONCLUSION}

CBDE with antegrade stent placement is an attractive alternative to T-tube placement in patients undergoing CBDE. The morbidity associated with T-tube and the need for TTC is avoided, hence enabling a faster recovery and return to work interval in such patient cohort.

\section{KEYWORDS}

Antegrade Stenting, Choledocholithiasis.

HOW TO CITE THIS ARTICLE: Swamygowda NN, Setty BN, Govindaiah SK, et al. Primary closure of CBD with antegrade stenting for choledocholithiasis. J. Evolution Med. Dent. Sci. 2017;6(48):3681-3685, DOI: 10.14260/Jemds/2017/795

\section{BACKGROUND}

Traditional surgical management of Common Bile Duct (CBD) stones has consisted of supraduodenal choledocholithotomy and insertion of a T-tube. The need for a more morbid open procedure and the inconvenience caused by a T-tube dangling by the side of the patient are being questioned. With the coming of age of laparoscopy and endoscopic techniques, the treatment for stone disease is seeing new horizons. More

Financial or Other, Competing Interest: None.

Submission 08-05-2017, Peer Review 02-06-2017,

Acceptance 09-06-2017, Published 15-06-2017.

Corresponding Author:

Dr. Balakrishna Nanjundappa Setty,

Department of Surgical-Gastroenterology,

PMSSY, Victoria Hospital,

Bangalore Medical College and Research

Institute, Bangalore-560002.

E-mail: drbalakrishna@live.com

DOI: $10.14260 /$ jemds $/ 2017 / 795$ and more patients are undergoing ERC followed by a simple laparoscopic cholecystectomy, as the experience with minimally invasive techniques continues to rise.

Laparoscopic CBD exploration with either primary closure of CBD after ensuring complete clearance of stone disease or internal drainage of the biliary system via stents is fast becoming a preferred modality of treatment in this patient cohort.

The debate if laparoscopic approach is feasible has long been settled. We aim to throw some light on the issue of closure techniques of CBD (over a T-tube or over a biliary stent) with our experience.

The purpose of this study is to evaluate the feasibility, safety and postoperative complications of primary closure of choledochotomy over a stent following successful common bile duct exploration by Open/Laparoscopic approach. 


\section{MATERIALS AND METHODS}

A retrospective descriptive study (audit) was performed from the database of our hospital for those patients who underwent primary closure of the CBD with antegrade stenting (both laparoscopic and open) and T-tube drainage during the period of $2007-2015$.

A systematic record review with review of the operative notes with special emphasis on intraoperative findings and post-procedural complications were carried out.

\section{Inclusion Criteria}

- All patients with confirmed CBD stones on imaging.

- $\quad$ Age group $>14$ years.

- $\quad$ CBD diameter of $>/=8 \mathrm{~mm}$.

- Mild-to-moderate cholangitis.

\section{Exclusion Criteria}

- Elderly patients aged beyond 75 years of age and/or with severe co-morbid illnesses.

- $\quad$ Patients with acute severe suppurative cholangitis and severe acute biliary pancreatitis.

- $\quad$ CBD diameter $<8 \mathrm{~mm}$ on imaging.

- Previous biliary surgery.

- Patient preference for alternative procedure.

Demographic data of the study group like age, sex, etc. were collected. Detailed history of presenting complaints, duration of illness and clinical data were recorded. Special emphasis was laid on the intraoperative findings, method of closure of the CBD and post-operative complications.

Patients were divided into two groups- Group I, those undergoing primary duct closure with antegrade stenting. Group II, those undergoing T-tube insertion.

Statistical analysis was done using student ' $\mathrm{t}$ ' test and simple statistical calculation of mean.

\section{Procedure}

Standard laparoscopic ports were placed for patients who underwent laparoscopic CBD exploration and a right subcostal incision was placed in those who underwent open procedure.

Hepatic flexure was taken down and the duodenum kocherised. All patients underwent a supraduodenal longitudinal choledochotomy after ensuring the identification of the relevant anatomy. Bile was aspirated and sent for culture and sensitivity in all patients.

Patients in Group 1 had a choledochoscope inserted via the choledochotomy and stones extracted. Visual confirmation of clearance of stone burden was ascertained in all patients before proceeding further. Choledochoscope was used to visualise up to second order ducts of the biliary system and the distal CBD until the ampulla, a standard procedure followed for cholecystectomy. A $7 \mathrm{~cm} \mathrm{x} \mathrm{7-Fr} \mathrm{or} \mathrm{a}$ $10-F r \times 12 \mathrm{~cm}$ stent was placed into the CBD prior to closure. Choledochotomy was closed with absorbable sutures (Polyglactin or Polydioxonane).

Patients in Group 2 were also subjected to a similar operative intervention. CBD stone clearance was done using a Desjardins forceps and irrigation after insertion of a 6-Fr infant feeding tube/8-Fr Foleys catheter into the CBD. After ensuring no stone on either trawling or in the return fluid, stone clearance was also confirmed by intraoperative cholangiogram. A Kehr's T-tube was trimmed to a horizontal limb length of approximately $6 \mathrm{~cm}$, the back wall trimmed and $a$ ' $V$ ' cut placed at the junction before insertion. The $\mathrm{T}$ tube was placed at the lower end of the choledochotomy. Cholecystectomy completed and choledochotomy closed using absorbable interrupted sutures. The T-tube was brought out through a stab incision on the abdominal wall separate from the main surgical incision. A 28-Fr drainage tube was also placed in the hepatorenal pouch selectively on a case to case basis.

\section{RESULTS}

During the study period, a total of 88 patients were operated. CBD stones were confirmed in all patients either with transabdominal ultrasound or MRCP as the imaging modality. The study group had a mean CBD diameter of $15 \mathrm{~mm}$ (range 8 - $19 \mathrm{~mm}$ ). Group I had 65 patients with Laparoscopic CBDE (Common Bile Duct Exploration) performed in 6, Lap converted to open in 11 and open CBDE in 48. Most of the patients were in the age group 41 - 50 years (Range $18-75$ years, Mean 37 years). A total of 39 (60\%) females and 26 (40\%) males underwent surgery in the study timeframe. Most frequent presenting complaint was obstructive pattern of jaundice $(33 \%)$ followed by right upper quadrant pain $(19 \%)$, fever (8\%) and a combination of these in $40 \%$.

$28(43 \%)$ patients were posted for surgery without an ERCP attempt in view of large stone size. The rest underwent (LCBDE- Laparoscopic Common Bile Duct Exploration/ OCBDE- Open Common Bile Duct Exploration) in view of partial stone clearance/failed ERCP). All patients had either a 7 -Fr $\times 7 \mathrm{~cm}$ or 10 -Fr $\times 12 \mathrm{~cm}$ biliary stent placed in the CBD prior to closure of the CBD.

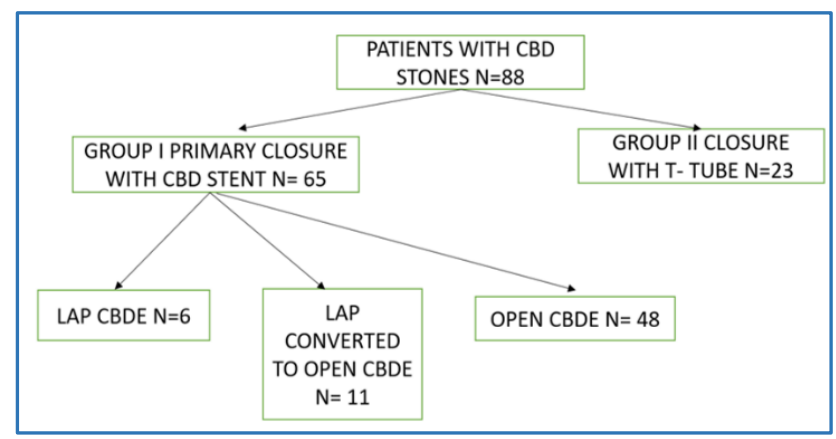

Figure 1. Flow Chart of Distribution of Patients

The average operative duration in the open CBDE was 146 mins, whereas the LCBDE arm had a mean duration of 186 mins. The laparoscopy converted to open cases have been included under the OCBDE group for statistics; 58 (90\%) of them were started on an oral diet on post-operative day 1 and drain removed on post-operative day 4 in 61 patients (95\%).

The mean hospital stay was 3 days for LCBDE patients (Range 2 - 4) and 5 days for OCBDE patients (Range 3 - 7); 6 patients (9\%) developed surgical site infection of the wound, which was managed conservatively. One of the patients in this group had a post-operative bile leak (low output), which settled with conservative management. The rest of the patients in the study group did not require any re-intervention or repeated imaging. 
There was no mortality in the study group. All stents were removed by Endoscopy, minimum $3-4$ weeks after the surgery. Liver function test and ultrasonography of the abdomen was done prior to removal of the stent.

\begin{tabular}{|c|c|c|}
\hline Parameter & $\begin{array}{l}\text { Primary Closure } \\
(n=65)\end{array}$ & $\begin{array}{l}\text { T-Tube } \\
(n=23)\end{array}$ \\
\hline Age & $18-75(37)$ & $26-75(50)$ \\
\hline Gender M:F (Ratio) & $26: 39(4: 6)$ & $9: 12(1: 1.3)$ \\
\hline Open & 48 & 23 \\
\hline $\begin{array}{c}\text { Laparoscopy } \\
\text { converted to open }\end{array}$ & 11 & - \\
\hline Laparoscopic & 6 & - \\
\hline \multicolumn{3}{|c|}{$\begin{array}{c}\text { Table I. Demographic Details and } \\
\text { Surgical Technique Followed }\end{array}$} \\
\hline
\end{tabular}

\section{Preoperative Laboratory Data}

The preoperative laboratory data were compared with that of primary closure group. Mean AST level (123.67 \pm 102.67 IU) and ALT level $(112.57 \pm 139.54 \mathrm{IU})$ were significantly higher in the primary closure group compared to T-tube group.

\begin{tabular}{|c|c|c|}
\hline & Primary Closure & T-Tube \\
\hline $\begin{array}{c}\text { Total Count } \\
\left(/ \mathrm{mm}^{3}\right)\end{array}$ & $\begin{array}{c}8757.14 \pm 3384.16 \\
(7500)\end{array}$ & $\begin{array}{c}8186.96 \pm 2480.16 \\
(7800)\end{array}$ \\
\hline Total & $4.67 \pm 3.23$ & $5.54 \pm 4.92$ \\
Bilirubin $(\mathrm{mg} \%)$ & $(3.5)$ & $(2.5)$ \\
\hline $\begin{array}{c}\text { S. albumin } \\
(\mathrm{mg} \%)\end{array}$ & $\begin{array}{c}3.36 \pm 0.49 \\
(3.30)\end{array}$ & $\begin{array}{c}3.24 \pm 0.40 \\
(3.20)\end{array}$ \\
\hline AST (IU) & $\begin{array}{c}123.67 \pm 102.67 \\
(60.00)\end{array}$ & $\begin{array}{c}67.65 \pm 44.12 \\
(39.00)\end{array}$ \\
\hline \multirow{2}{*}{ ALT (IU) } & $\begin{array}{c}112.57 \pm 139.54 \\
(92.00)\end{array}$ & $\begin{array}{c}52.26 \pm 49.02 \\
(46.00)\end{array}$ \\
\hline \multirow{2}{*}{ ALP (IU) } & $\begin{array}{c}333.05 \pm 272.71 \\
(224.00)\end{array}$ & $\begin{array}{c}222.39 \pm 211.75 \\
(162.00)\end{array}$ \\
\hline \multicolumn{2}{|c}{ Table II. Comparison of Liver Function Test }
\end{tabular}

Data presented as mean \pm SD (Median).

AST $=$ Aspartate transaminase

ALT $=$ Alanine transaminase

$\mathrm{ALP}=$ Alkaline phosphatase .

\begin{tabular}{|c|c|c|}
\hline & Primary Closure & T-Tube \\
\hline Biliary Complications & & \\
\hline$\bullet \quad$ Bile leakage & 2 & 2 \\
\hline$\bullet \quad$ Peritonitis & 0 & 1 \\
\hline$\bullet \quad$ Slippage of tube & NA & 1 \\
\hline$\bullet \quad$ Retained stone & 0 & 1 \\
\hline$\bullet \quad$ Peritubal leak & NA & 3 \\
\hline$\bullet \quad$ Port site infection & 2 & NA \\
\hline$\bullet \quad$ Blocked stent & 1 & NA \\
\hline Other Complications & & \\
\hline$\bullet \quad$ Wound infection & 3 & 3 \\
\hline$\bullet \quad$ Respiratory infection & 1 & 2 \\
\hline$\bullet \quad$ Urinary retention & 1 & 0 \\
\hline$\bullet \quad$ Mortality & 0 & 1 \\
\hline \multicolumn{2}{|c|}{ Table III. Postoperative Complications } \\
\hline
\end{tabular}

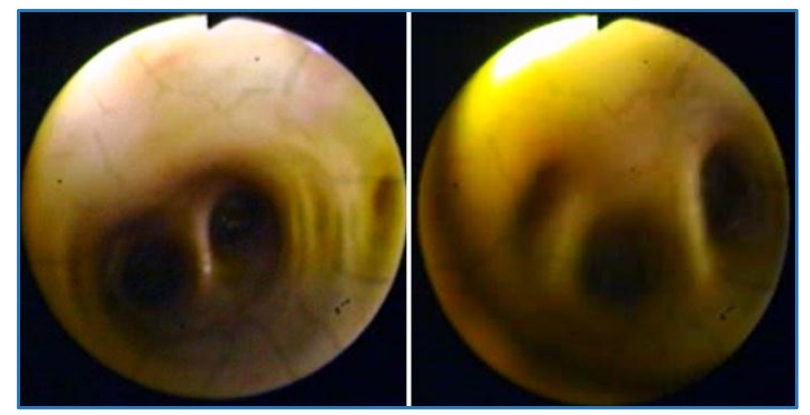

Figure 2. Choledochoscopic View of Intrahepatic Ducts

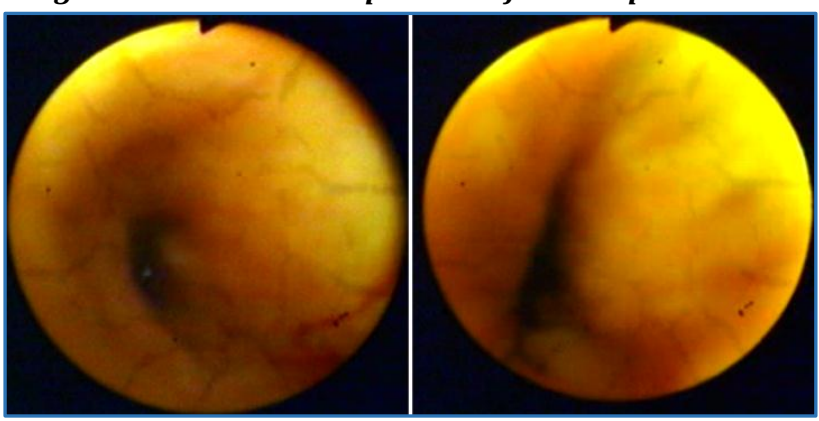

Figure 3. Lower CBD View of Sequential Opening of Sphincter of Oddi with Air Insufflation

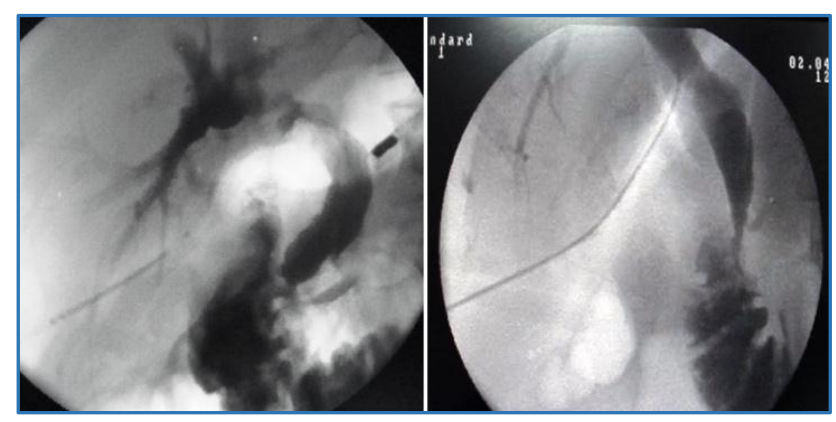

Figure 4. Completion of Cholangiogram showing Free Flow of Contrast into the Duodenum

In Group II study, 23 patients had T-Tube drainage as the primary modality of closure after CBD exploration. Patients were aged between 26 and 75 years with a median age of 50 years.

As with primary closure group, biliary colic was the most common presenting symptom $(10 / 23)$ followed by jaundice $(4 / 23)$. Two patients had cholangitis and seven patients presented with various combinations of the above.

The mean diameter of CBD on IOC was $13.39 \pm 3.38 \mathrm{~mm}$. Majority of patients had single stone $(69.56 \%)$ and the maximum number of stones in a single patient being 5 .

The mean operative time in T-tube group was $113.26 \pm$ 21.62 mins. All patients underwent T-tube cholangiogram between postoperative days 5 - 6 . Repeat cholangiogram done after 2 weeks, if normal T-tubes were removed. Seven patients had a total of 12 complications (30.43\%).

Biliary complications occurred in 6 patients $(26.08 \%)$. One patient had bile leak leading to biliary peritonitis with the T-tube in-situ. Patient underwent reoperation, but succumbed to sepsis and multiorgan failure. One patient had accidental tube slippage on postoperative day 5 with no further complications. One patient with retained stone detected on T-tube cholangiogram on postoperative day 10 , underwent ERCP and stone extraction. Three patients had 
peritubal leak with local skin excoriation necessitating usage of antibiotics. Three patients had wound infection.

\section{DISCUSSION}

The first surgical exploration of the CBD was reported as early as 1889 by a Swiss surgeon, Ludwig Courvoisier. ${ }^{1}$ Since then, for many decades open cholecystectomy and CBD exploration with a T-tube closure have been the GOLD standard treatment for patients with combined gall stones and choledocholithiasis. Morbidity and mortality associated with these procedures have been low. The percentage of retained stones only $1 \%-3 \%$, and during long-term followup revisional surgery was necessary in about $10 \%$ of the patients. $^{2-5}$ With the advent of minimal access surgical techniques and endoscopic access to our armamentarium, the modern surgeons' experience with the traditional open CBD exploration is fast decreasing.

In the 1880's CBD stones were either milked back into the gall bladder for extraction by cholecystectomy or crushed in the CBD for easier passage of stone fragments.

The 1970s saw the introduction of Endoscopic Sphincterotomy (ES) as a treatment modality for common bile duct stones. ${ }^{6,7}$ With fast acceptance of this less invasive and highly effective alternative treatment modality, the Ttube era had truly begun to end. However, in patients with residual stones in the gallbladder, subsequent cholecystectomy was considered necessary. In a prospective randomised trial, it was demonstrated that Endoscopic Sphincterotomy before (open) cholecystectomy did not lead to earlier recovery or less postoperative morbidity as compared to primary open cholecystectomy combined with common bile duct exploration. 4

For the elderly and surgically unfit patients, the introduction of ES was a boon. The chance of a subsequent attack of biliary events was put at a meagre $10 \%$, which when compared against the risk involved in a surgical procedure was far lesser. However, in a high-risk patient or in a young and fit patient cholecystectomy after ES is mandatory to avoid future complications of a slipped or migrated stone from the in situ gall bladder.

With minimally invasive surgery gaining acceptance across the globe and emergence of ES, the need for a CBD exploration was challenged. ES followed by laparoscopic cholecystectomy became the norm in the years to follow, thus avoiding the morbidity and mortality of a CBD exploration. With increase in a global experience with laparoscopy, exploration of the CBD via a laparoscope rekindled the debate of which modality was better for patients with choledocholithiasis. Intraoperative cholangiography helped justify the laparoscopic CBD exploration believers. A routine intraoperative cholangiogram during cholecystectomy picks up CBD stones in approximately $10 \%-15 \%$ of patients. Approximately, $2 \%$ of patients also undergo an unnecessary surgical exploration of the CBD due to a false positive study.

The advantage of a laparoscopic CBD exploration is undeniable in those in whom stone extraction has been possible transcystically. Laparoscopic CBD exploration per se does add to the operative time, is technically more demanding and the rate of complications too see an upward trend.

Thus far, there has been no compelling evidence to choose one approach over the other. In high volume Minimal Access
Surgery Centres, Laparoscopic CBD exploration has the same morbidity and mortality rates as compared to ES followed by Laparoscopic cholecystectomy.

With the resurgence of the laparoscopic approach also came the question of management of the CBD after exploration. A C-tube or a transcystic tube can be left in place in patients with attempted and failed stone clearance. Passage of the C-tube across the ampulla also enables the subsequent endoscopist to easily identify and cannulate the duct. The alternative is to suture close the CBD over a T-tube or to primarily close the CBD after antegrade placement of an ERCP stent across the ampulla.

The pro T-tube brigade argue that the usage of T-tube allows the sphincter oedema to settle. The rise of biliary pressure secondary to such an event could lead to duct disruption at the suture line resulting in either low-grade biliary leaks or result in biliary peritonitis.

The above points are brought out in our study, wherein the patients in Group I (primary closure of CBD over stent) had early return to oral feeds, shorter duration of hospital stay and lesser postoperative complications compared to the Group II (T-tube insertion) patients.

The strongest point in favour of use of T-tube is detection and subsequent treatment of retained ductal stones through the T-tube itself. Failure to drain the duct may result in buildup of pressure in the extrahepatic ductal system, leading to leakage or disruption of duct closure with biliary peritonitis. Despite these potential advantages, the morbidity associated with the T-tube is high. Accidental displacement of the Ttube, biliary leakage, duodenal erosion, persistent biliary fistula, excoriation of the skin and cholangitis caused by micro-organisms migrating through the T-tube may prolong hospital stay and delay postoperative recovery.

A high incidence of infective complications was noted by Keighley. ${ }^{8}$

Risk of accidental dislodgement of T-tube is a constant threat and so is the risk of dyselectrolaemia and dehydration. The need for extra hospitalisations and in-hospital procedures, such as T-tube cholangiograms are also needed. These complications outweigh the benefits offered by the $\mathrm{T}$ tube, especially because the short- and long-term results of primary closure or closure over a stent are favourable. $9-15,16-21$

The T-tube does have a role in select patients in those with altered anatomy, such as after a Billroth II reconstruction where endoscopic access to the papilla is not possible. In patients with a failed pre-operative ERCP or when a stone clearance cannot be confirmed per operatively, placement of an indwelling tube (T-tube) is mandatory.

Alternate methods of biliary drainage post exploration have also been tried such as a percutaneous transhepatic biliary drainage catheter or an endonasal biliary catheter. But none have been more easier to handle than a stent placement.

Advances in endoscopy such as intraoperative choledochoscopy and endoscopic retrograde cholangiopancreaticography have resulted in a decreased incidence of retained CBD stones as well as an alternative method for their extraction.

A study by Dorrian et al also has proved the safety, feasibility and superiority of antegrade stenting of CBD over T-tube drainage of the CBD. ${ }^{22}$ Insertion of antegrade stent or endoprosthesis that crosses the papilla provides biliary 
drainage/decompression and also facilitates a postoperative ERCP if required.

With the combination of minimal access surgical exploration of CBD and medical grade stents available, the era of T-Tube is well and truly over.

\section{CONCLUSION}

Primary closure of choledochotomy over a biliary stent is a safe procedure. The procedure can be safely performed in most of the patients with choledocholithiasis after lap/open CBD exploration.

The routine use of intraoperative choledochoscopy and completion cholangiography ensures complete clearance and patency of the common bile duct.

The complications that occur following primary closure are usually minor and can be managed easily.

The routine use of T-tube may not be necessary, because of the discomfort associated with it until its removal.

\section{REFERENCES}

[1] Courvoisier L. Casuistisch: statistische beitrage zur pathologie und chirurgie der Gallenwege. Leipzig Vogel 1890;387:57e58.

[2] Gonzales JJ, Sanz L, Grana JL. Biliary lithiasis in the elderly patient: morbidity and mortality due to biliary surgery. Hepatogastroenterology 1997;44(18):1565-8.

[3] Hammarstrom LE, Holmin T, Stridbeck H, et al. Longterm follow-up of a prospective randomized study of endoscopic versus surgical treatment of bile duct calculi in patients with gallbladder in situ. Br J Surg 1995;82(11):1516-21.

[4] Neoptolemos JP, Carr-Locke DL, Fossard DP. Prospective randomised study of preoperative endoscopic sphincterotomy versus surgery alone for common bile duct stones. BMJ (Clin Res Ed) 1987;294(6570):470-4.

[5] Targarona EM, Ayuso RMP, Bordas JM, et al. Randomised trial of endoscopic sphincterotomy with gallbladder left in situ versus open surgery for common bile duct calculi in high-risk patients. Lancet 1996;347(9006):926-9.

[6] Classen M, Demling L. Endoscopic sphincterotomy of the papilla of Vater and extraction of stones from the choledochal duct. Dtsch Med Wochenschr 1974;99(11):496-7.

[7] Kawai K, Akasaka Y, Murakami K, et al. Endoscopic sphincterotomy of the amulla of Vater. Gastrointest Endosc 1974;20(4):148-51.
[8] Keighley MR, Burdon DW, Baddeley RM, et al. Complication of supraduodunal choledochotomy: a comparison of three methods of management. $\mathrm{Br} \mathrm{J}$ Surg 1976;63(10):754-8.

[9] Mirizzi PL. Primary suture of the common bile duct in choledocholithiasis. Arch Surg 1942;44(1):44-54.

[10] Collin PG, Redwood CRM, Wynne-Jones G. Common bile duct without intraductal drainage following choledochotomy. Br J Surg 1960;47(206):661-7.

[11] Sawyers JL, Herrington JL, Edwards WH. Primary closure of the CBD. Am J Surg 1965;109:107-12.

[12] Collin PG. Further experience with common bile-duct suture without intraductal drainage following choledochotomy. Br J Surg 1967;54(10):854-6.

[13] Vassilakis JS, Chattopadhyay DK, Irvin TT, et al. Primary closure of common bile duct after elective choledochotomy. J R Coll Surg Edinb 1979;24(3):1568.

[14] Sorensen VJ, Buck JR, Chung SK, et al. Primary common bile duct closure following exploration of the common bile duct: an effective alternative to routine biliary drainage. Am Surg 1994;60(6):451-4.

[15] Seale AK, Ledet WP. Primary common bile duct closure. Arch Surg 1999;134(1):22-4.

[16] Moreaux J. Traditional surgical management of common bile duct stones: a prospective study during a 20-year experience. Am J Surg 1995;169(2):220-6.

[17] Ha JP, Tang CN, Siu WT, et al. Primary closure versus T-tube drainage after laparoscopic choledochotomy for common bile duct stones. Hepatogastroenterology 2004;51(60):1605-8.

[18] Sikic N, Tutek Z, Strikic N. Primary suture vs. T-tube after common bile duct exploration (our 25 years of experience). Przegl Lek 2000;57 (Suppl 5):143-5.

[19] Martin IJ, Bailey IS, Rhodes M, et al. Towards T-tube free laparoscopic bile duct exploration: a methodologic evolution during 300 consecutive procedures. Ann Surg 1998;228(1):29-34.

[20] Williams JA, Treacy PJ, Sidey P, et al. Primary duct closure versus $\mathrm{T}$-tube drainage following exploration of the common bile duct. Aust N Z J Surg 1994;64(12):823-6.

[21] Payne RA, Woods WG. Primary suture or T-tube drainage after choledochotomy. Ann R Coll Surg Engl 1986;68(4):196-8.

[22] Dorrian E, Jones C, Warren C, et al. Laparoscopic CBD exploration and the long-term effect of ante-grade biliary stents. HPB 2016;18(Suppl 2):e666. 